\title{
Corrigendum
}

\section{Infection prevention in the operating room anesthesia work area - CORRIGENDUM}

On page 5 of the expert guidance article by Munoz-Price $e t$ al, ${ }^{1}$ the authors offer the following addition to clarify the statement "Stopcocks should have closed injection ports installed to convert them into "closed ports," or they should be covered with sterile caps." If stopcocks are not being used to inject drugs, they should at least be covered with sterile caps.

On page 6 of the expert guidance article by Munoz-Price $e t a l,{ }^{1}$ the statement "The package inserts for propofol that contain a preservative typically specify that the use of propofol should commence within 12 hours of preparation" is incomplete.

It should instead read, "The package inserts for propofol that contain a preservative typically specify that the use of propofol should commence promptly and be completed within 12 hours of preparation."

The authors apologize for this error.

\section{Reference}

1. Munoz-Price, L, Bowdle, A, Johnston, BL, et al. Infection prevention in the operating room anesthesia work area. Infect Control Hosp Epidemiol 2019;40: 1-17. 